\title{
Understanding Patients' Willingness to Pay for Biphasic Insulin Aspart 30/70 in a Pen Device for Type 2 Diabetes Treatment in an Out-of-Pocket Payment Market
}

\author{
Sreenivasa Murthy ${ }^{1}$ Pankaj Aneja ${ }^{2}$ - Arthur Joseph Asirvatham ${ }^{3} \cdot$ Lise Lotte N. Husemoen $^{4} \cdot$ Nicolai A. Rhee $^{5}$. \\ Jothydev Kesavadev ${ }^{6}$
}

Accepted: 10 December 2020 / Published online: 6 January 2021

(c) The Author(s) 2021

\begin{abstract}
Objective Our objective was to investigate willingness to pay (WTP) for biphasic insulin aspart 30/70 (BIAsp 30) in patients with type 2 diabetes mellitus (T2DM) in India.

Methods A multicenter, prospective, non-interventional, preference study was conducted that assessed WTP for BIAsp 30 in an insulin pen $\left(\right.$ FlexPen ${ }^{\circledR}$ or Penfill ${ }^{\circledR}$ device) in patients in India with T2DM previously treated with biphasic human insulin (BHI) in vials and believed to be able to pay for treatment. The primary endpoint was the proportion of patients willing to continue to pay for BIAsp 30 after 12 weeks' treatment. Secondary endpoints included the change from baseline in treatment and device satisfaction and patient preferences for treatment attributes as assessed by a nested discrete-choice experiment. Results Overall, $54.9 \%(n=277 / 505)$ of participants were male; the mean age was 56.4 years; diabetes duration was 10.9 years; $63.8 \%$ had a body mass index $\geq 25 \mathrm{~kg} / \mathrm{m}^{2} ;>75 \%$ had an annual household income $>150,000$ Indian rupees (INR). After 12 weeks' treatment, $96.4 \%$ of patients were willing to pay for BIAsp 30. Mean treatment and device satisfaction significantly improved from baseline $(p<0.0001)$. Patients were willing to pay INR3576 (95\% confidence interval [CI] 2755-4398) for improved glycemic control, INR688 (95\% CI 383-994) for a device upgrade (vial/syringe to an insulin pen), or INR327 (95\% CI 95-560) to avoid major hypoglycemia. Patients would need to be compensated INR44 (95\% CI 56-32) per minor hypoglycemic event.
\end{abstract}

Conclusions In India, patients with T2DM previously treated with BHI were willing to pay for BIAsp 30 in an insulin pen. Furthermore, treatment and device satisfaction improved after this therapeutic switch.

Trial Registration ClinicalTrials.gov: NCT03374774.

\section{Introduction}

While the number of people with diabetes is growing worldwide, the largest increase is occurring in regions where economies are moving from low- to middle-income levels [1]. India was estimated to have 72.9 million people with diabetes in 2017 and is predicted to lead the world with the highest number of people with diabetes in 2045, with 134.4 million [2]. The majority of these people will have type 2 diabetes mellitus (T2DM) [2]. Given the progressive

Supplementary Information The online version contains supplementary material available at https://doi.org/10.1007/s4166 9-020-00246-3.

Sreenivasa Murthy

drsreenivasamurthy@gmail.com

Extended author information available on the last page of the article nature of T2DM, most people will require insulin therapy to achieve and maintain glycemic targets [3]. Premix insulins are the most frequently prescribed insulin therapy for T2DM in many low- to middle-income regions, including India and many parts of Asia, and provide both fasting and post-meal glycemic control $[4,5]$. Additionally, some people in these countries rely on traditional vials and syringes and have not adopted the more recently developed delivery devices (such as insulin pen-injectors) that are now available [6, 7]. Compared with vials and syringes, insulin pen-injector devices are easier to use, less painful, faster to teach, more discrete to use in public, and offer superior dosing accuracy, improved patient satisfaction, reduced anxiety regarding self-injection, and improved confidence in glycemic control [8-12].

Biphasic insulin aspart 30/70 (BIAsp 30) is a premix insulin comprising rapid-acting insulin aspart and intermediate-acting protamine-crystallized insulin aspart in a 30:70 


\section{Key Points for Decision Makers}

As patients must self-fund healthcare costs in out-ofpocket payment markets such as India, it is important that prescribers understand the factors influencing patient preferences and willingness to pay for a treatment.

In a real-world clinical setting, after 12 weeks' treatment, the vast majority of patients with type 2 diabetes mellitus in India who participated in a prospective non-interventional study were willing to pay to switch from biphasic human insulin in vials to biphasic insulin aspart 30/70 in a pen device; overall treatment and device satisfaction were significantly improved after this therapeutic switch $(p<0.0001)$.

Furthermore, the most important treatment attributes to patients were as follows (in rank order of importance): improvement in glycemic control, a device upgrade (vial and syringe to an insulin pen), and avoidance of hypoglycemia.

ratio [13]. Switching from biphasic human insulin (BHI) to BIAsp 30 has been shown to reduce postprandial glucose excursions, with fewer nocturnal and major hypoglycemic episodes [14]. Additionally, whereas BHI must be injected 30 minutes before a meal, BIAsp can be administered immediately before a meal, or soon after if necessary, giving patients flexibility in insulin administration [4]. BIAsp 30 has a simple dose-titration algorithm, and treatment can be intensified from a once-daily dose up to thrice-daily injections with meals, representing an alternative to basal-bolus therapy with fewer daily injections [15].

A key feature of healthcare in low- and middle-income countries is that patients often must self-fund healthcare costs. Therefore, it is important for prescribers to understand the factors that influence patient preferences and willingness to pay (WTP) for a treatment. WTP is a measure of the maximum amount of money an individual is willing to pay to procure goods or a service [16]. A number of attributes can impact a patient's preference for a treatment, including dosage, required frequency, ease of use, side effects, and cost [17-19]. WTP can be derived from discrete-choice experiments (DCEs), an approach that assesses the relative importance of treatment attributes and the patient's WTP to obtain or avoid attributes [17]. WTP analyses via DCEs have been applied to a wide range of interventions in different markets, including insulin therapy $[17,18,20]$.

Limited data are available evaluating patients' WTP for insulin analog treatment in countries with mainly out-ofpocket payment markets, such as India. This study investigated WTP for BIAsp 30 treatment in patients with T2DM in India, and highlighted their preferences for BIAsp 30 attributes and overall satisfaction with their treatment and delivery device.

\section{Methods}

\subsection{Indian Healthcare System}

Each state in India is required to provide free universal access to healthcare services; however, issues with access to, and the quality of, public healthcare providers has resulted in a dominant private healthcare sector where costs are typically paid out of pocket [21]. Out-of-pocket payments accounted for $58.7 \%$ of total Indian health expenditure in 2016-2017 [22]. Various public insurance schemes are available for individuals living below the poverty line, in addition to private health insurance schemes with varying levels of coverage, cost sharing, and out-of-pocket costs [21].

\subsection{Study Design}

This was a 12-week, multicenter, non-interventional, prospective, preference study, assessing WTP for BIAsp 30 in an insulin pen $\left(\right.$ FlexPen ${ }^{\circledR}$ ) or insulin pen cartridge $\left(\right.$ Penfill $\left.{ }^{\circledR}\right)$ device (Novo Nordisk A/S, Denmark) in patients with T2DM previously treated with BHI in vials using syringes (Clinicaltrials.gov; NCT03374774). Data were collected at a baseline visit (defined as the first prescription of BIAsp $30)$ and following an observational period of 12 weeks ( \pm 14 days) (Fig. 1). The primary endpoint was the proportion of participants willing to continue to pay for BIAsp 30 after 12 weeks' treatment. It should be noted that WTP was defined as being willing to pay a given price (the out-ofpocket treatment cost; Table 1 in the electronic supplementary material [ESM]) for BIAsp 30, rather than a measure of the maximum amount of money that an individual is willing to pay for BIAsp 30 treatment, i.e., it was a relevant measure of WTP. Secondary endpoints included the change from baseline in treatment and device satisfaction, and participant preferences for treatment attributes, as assessed by a nested DCE.

\subsection{Patients}

Patients were recruited at 19 urban and semi-urban sites from 15 cities across India representing private clinics, private hospitals, and private teaching hospitals (Table 2 in the ESM). Sites were selected if they had previous experience with non-interventional studies, the capacity to conduct a clinical study, and previous experience with premix insulin prescriptions. A further site selection criterion was geographical representation. At the selected sites, a total of 
30 physicians who regularly treated patients with T2DM participated in the study.

Eligible patients were adults (aged $\geq 18$ years) diagnosed with T2DM and receiving BHI treatment in vials for $\geq 3$ consecutive months at time of informed consent. Eligible patients were selected by their treating physician as likely to be able and willing to pay for the BIAsp 30 treatment for $\geq 12$ weeks from baseline. The decision to initiate treatment with BIAsp 30 was made by the patient and physician before and independently from study participation. Exclusion criteria were previous treatment with an insulin analog; concurrent participation in another clinical trial or study; known or suspected hypersensitivity to study product or related products; mental incapacity, unwillingness, language barriers precluding adequate understanding or cooperation; and being unable to read or write. Consecutive patients who satisfied the eligibility criteria were invited to participate in the study.

\subsection{Assessments}

Secondary endpoints were assessed via questionnaires and a nested DCE, which were translated into 11 local languages. An ability-to-pay questionnaire was used to infer patients' ability to pay for BIAsp 30 treatment and to obtain demographic and socioeconomic data (Appendix 1 in the ESM). Patients' medical records were accessed by the physician or an authorized delegate to collect relevant and available data for a physician's questionnaire to obtain additional demographic and clinical data, in addition to the treating physician's reasons for switching the patient to BIAsp 30 treatment (Appendix 2 in the ESM). A nested DCE assessed

Decision to switch to BIAsp is made by patient and treating physician, before and independently of study

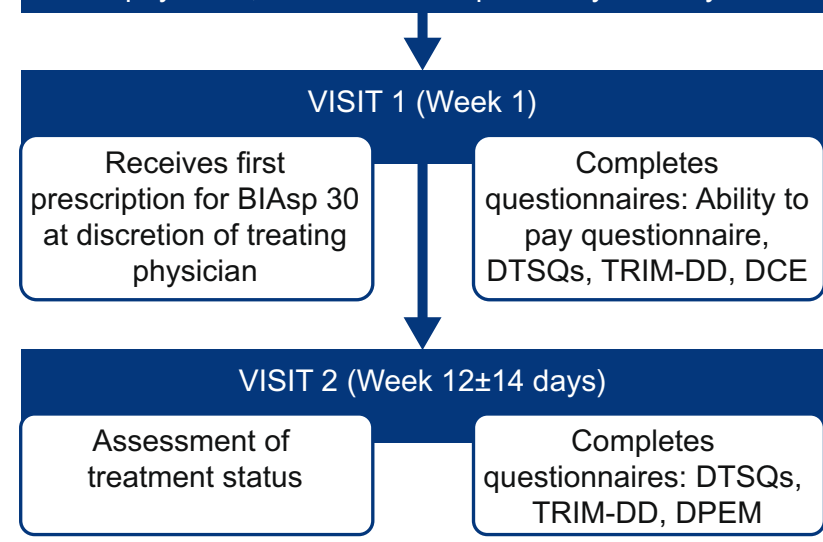

Fig. 1 Study design. BIAsp 30 biphasic insulin aspart 30, DCE discrete-choice experiment, DPEM Diabetes Pen Experience Measure, DTSQ Diabetes Treatment Satisfaction Questionnaire, TRIM-DD Treatment-Related Impact Measure for Diabetes Device patients' WTP [in Indian rupees (INR), year 2018 values] and preferences for BIAsp 30 treatment attributes (described in detail in the following).

Satisfaction with BIAsp 30 treatment in an insulin pen was assessed using the Diabetes Treatment Satisfaction Questionnaire (DTSQ) [23], which consisted of eight items: six related to treatment satisfaction, and one item each on perceived frequency of hyperglycemia and hypoglycemia (Appendix 3 in the ESM). Responses were recorded on a scale from 0 to 6 , where 0 was "very dissatisfied" or "infrequently" and 6 was "very satisfied" or "frequently". The six treatment satisfaction items were combined to obtain the DTSQ score (maximum of 36). Perceived frequency of hyperglycemia and hypoglycemia scores were analyzed separately.

Device satisfaction was assessed using the TreatmentRelated Impact Measure for Diabetes Device (TRIM-DD; Appendix 4 in the ESM), which consisted of three items across two domains (bother, function), and responses were scored on a scale from 1 to 5; a higher score indicated a less negative impact [24] (Appendix 4 in the ESM). Device bother and function domain scores were computed by summing across items in the same domain. For the bother domain score, responses were inversed for intuitive interpretation such that a higher score indicated less bother. Device satisfaction was further assessed using a novel questionnaire currently in development-the Diabetes Pen Experience Measure (DPEM) questionnaire-which consisted of seven items on a 5- or 6-point scale (Appendix 5 in the ESM).

This study did not assess any efficacy or safety endpoints outside of mandatory safety reporting (e.g., fatal outcomes or serious adverse events).

\subsection{Discrete-Choice Experiment}

The DCE approach uses random utility theory to model realistic treatment choices and estimate the relative importance of the decision-making factors. A DCE approach was selected to elicit patients' preferences for treatment attributes in a controlled experimental setting. The DCE followed the framework of the International Society for Pharmacoeconomics and Outcomes Research Conjoint Analysis Task Force checklist for good research practices [25]. Relevant treatment attributes and attribute levels for this study were identified through literature reviews, searches of online scientific methodology databases, and consultation with clinicians. The following treatment attributes and levels were selected as important factors in this study: device (vial/ syringe, insulin pen [complete with pre-filled cartridge], pre-filled insulin pen cartridge [for use in an insulin pen]), blood glucose control (glycated hemoglobin $\left[\mathrm{HbA}_{1 \mathrm{c}}\right]<7 \%$, $7-9 \%,>9 \%)$, minor hypoglycemia episodes $(0,4,12$, or 52 per year), major hypoglycemia episodes ( 0 or 1 per year), 
dosing flexibility ( 0 or 30 minutes before a meal), and cost (INR0, 225, 650, or 1650). Quantitative and qualitative pilot testing were performed to check that the mode of administration was appropriate, that the treatment attributes and levels were relevant to patients with T2DM in India, and that participants understood the test and did not find it overly burdensome.

The DCE was designed by Ngene ChoiceMetrics (Sydney, Australia), was orthogonal, and was administered using pen and paper. Patients were randomly assigned to view one block of eight treatment scenarios each, from a total of 24 unique scenarios. In addition, patients viewed one dominant scenario task (whereby all the attribute levels of one treatment scenario were better than the levels of the alternative scenario) to determine whether they understood the interpretation of each level (and were excluded from the main DCE analysis if they failed this task). In total, each patient completed five forced-choice tasks between two treatment scenarios each, where patients indicated which treatment they would prefer to take (refer to Fig. 2 for an example DCE task). While a forced choice may not be a realistic treatment scenario, it does force patients to make trade-offs and, thus, allows an assessment of the relative importance of treatment attributes. To avoid respondent fatigue, treatment scenarios were presented as partial profiles (i.e., each choice task involved a subset of the treatment attributes), no implausible combinations were included, and patients were not allowed to opt out from a task to maximize the information obtained on trade-offs [26].

\subsection{Statistical Analysis}

A sample size of at least 500 patients was targeted to ensure sufficient power, based on a literature search of previous methodologies. All analyses, excluding those for the DCE, were conducted using the full analysis set (FAS), which included all patients who attended the baseline and week12 visits within the given time window. Data were summarized descriptively. The primary endpoint-the proportion of patients using BIAsp 30 (in an insulin pen device) as their primary insulin after 12 weeks-was analyzed using an associated Wilson score. Based on the probability of using BIAsp 30 at week 12, patients were categorized according to those who were willing to pay (WTP) and those who were not (not WTP) for BIAsp 30. Data for these groups (WTP/ not WTP) were summarized descriptively and differences between groups compared using the chi-squared/Fisher's exact test (categorical variables) or the t-test (continuous variables). Scores at baseline and week 12 were compared using the Wilcoxon rank sum test for the DTSQ score, the raw bother and function domain scores (TRIM-DD), and the raw perceived frequency of hypoglycemia and hyperglycemia item scores (TRIM-DD).

DCE results were analyzed using mixed-logit models, with the main analysis conducted for patients who passed the

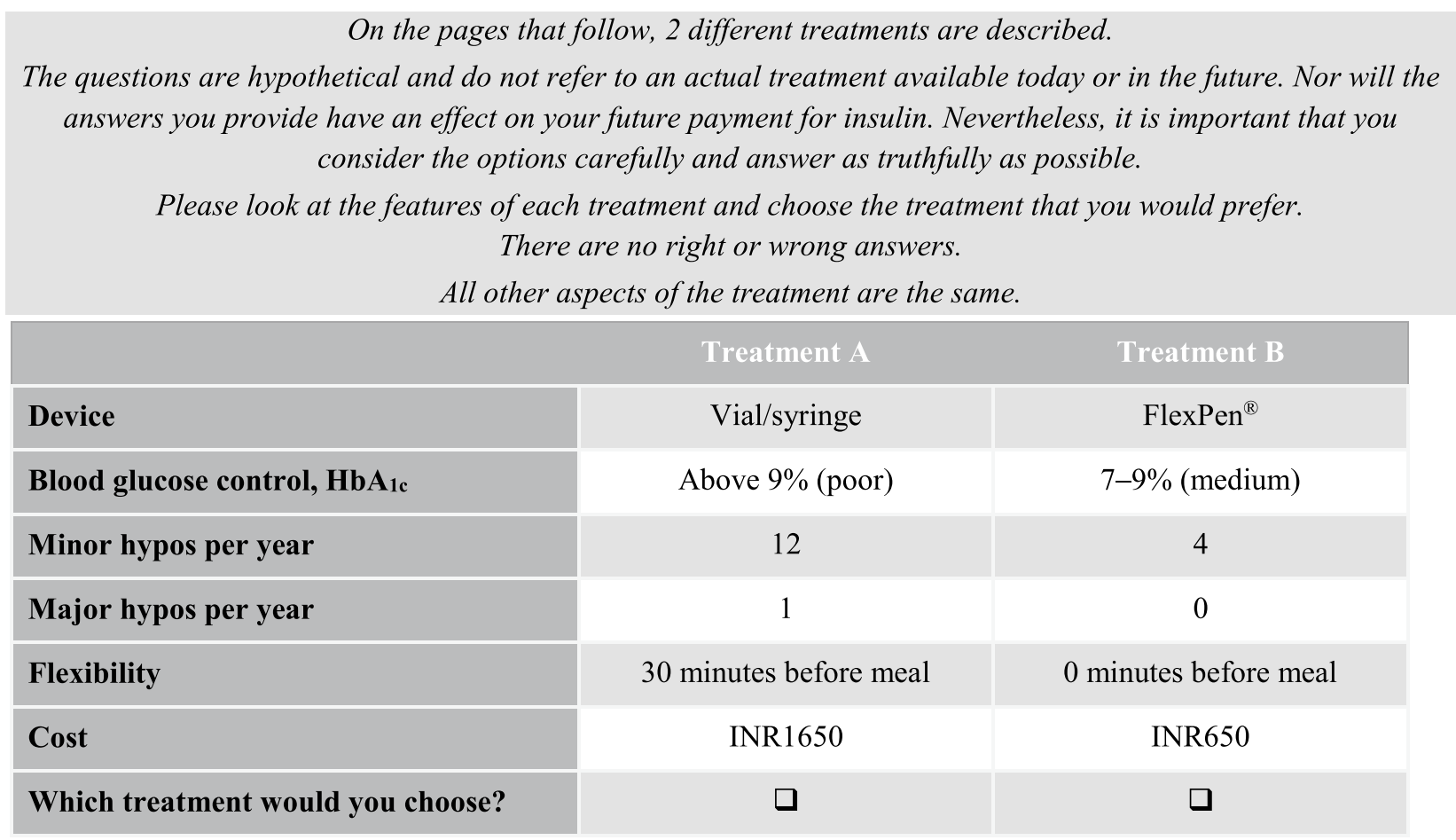

Fig. 2 Example discrete choice experiment task. $H b A_{1 c}$ glycated hemoglobin, INR Indian rupees 
dominant scenario task and a sensitivity analysis conducted for the FAS. Attributes were ranked by relative importance (the difference between the minimum and maximum coefficients of an attribute divided by the sum of differences across all attributes). WTP was calculated using this formula: $\mathrm{WTP}_{\mathrm{Y}}=-(\mathrm{d} Y /-\mathrm{dCost})$. Where $\mathrm{Y}$ is an attribute and $\mathrm{d}$ represents the utility change due to the change in the attribute. Subgroup analyses to examine preference heterogeneity were not conducted as they were considered out of the scope of the present study. To facilitate an international comparison, the 2018 exchange rate was INR $1=€ 0.0124$ (calculated as the weighted monthly average over the 12 -month period) [27].

Missing data were not imputed, and the number of missing data points are reported for each analysis. All tests of statistical significance were two sided and assessed at a significance level of $5 \%$.

\section{Results}

In total, 516 patients were recruited from November 13 , 2017, to March 31, 2018, with final visits up to July 4, 2018. Of these, 505 (97.9\%) patients completed their week 12 visit and were included in the final analysis; 11 patients were excluded from the analysis as their week 12 visit was outside the 14-day window. After 12 weeks' treatment, the majority of patients (96.4\% [95\% CI 94.4-97.7]; $n=487 / 505$ ) used BIAsp 30 as their primary insulin and were WTP for treatment.

Patient demographic and ability-to-pay characteristics according to WTP status are shown in Table 1 and Table 3 in the ESM. Among the total study population at baseline, $54.9 \%$ were male; the mean age was 56.4 years; $63.8 \%$ of patients had a body mass index $\geq 25 \mathrm{~kg} / \mathrm{m}^{2}$. Almost half of patients (46.1\%) had been diagnosed with diabetes for $>10$ years; the mean \pm standard deviation (SD) duration of diabetes was $10.9 \pm 7.12$ years. In addition to BHI, the most commonly reported anti-diabetes medications were metformin (79.8\%), sulfonylureas (61.8\%), and dipeptidyl peptidase-4 inhibitors (38.4\%). Comorbidities were reported by $>80 \%$ of patients, most commonly hypertension, hypercholesterolemia, neuropathy, kidney disease, and stroke/heart disease (Table 1).

The majority ( $>80 \%$ ) of patients resided in an urban area and owned their own house. In terms of current work status, just under $40 \%$ were in paid employment; those not in paid employment were either homemakers, retired, unemployed, or full-time students. More than three-quarters of patients had an annual household income higher than INR150,000, and more than one-quarter had an income higher than INR340,000. The majority ( $>60 \%$ ) were educated to senior secondary school level, and almost half of the patients had a university qualification. In terms of their children's education, more than half were educated privately, whereas approximately $5 \%$ of patients did not have children. Half of the patients were uninsured, whereas one-quarter had private health insurance, one-fifth had public health insurance, and less than 5\% had work-related healthcare insurance (Table 1). According to WTP status, significant differences $(p<0.05)$ were observed only for patients' educational status, their children's education, their credit card status, and the frequency of family visits to a restaurant (Table 1; Table 3 in the ESM).

\subsection{Physicians' Reasons for Switching Treatment and Evaluation of Willingness-to-Pay Status}

Physicians' reasons for switching patients from BHI to BIAsp 30 are shown in Table 4 in the ESM. The most common reason, cited by $95.0 \%$ of physicians, was to improve patients' blood sugar control. Other reasons cited included reducing the risk of hypoglycemia (87.5\%), improving flexibility of dosing (57.6\%), and/or ease of administration $(41.0 \%)$.

Most physicians ( $n=496,98.2 \%)$ believed that their patients (who participated in the study) would be "likely" or "very likely" to use BIAsp 30 in an insulin pen device as their primary insulin and device after 12 weeks' treatment; only seven (1.4\%) physicians believed that their patients were "unlikely" or "very unlikely" to use the treatment. The most common reasons cited for patients being "likely" or "very likely" to continue use of BIAsp 30 were a patient's compliance with clinical visits (40.2\%), knowledge of their family (35.6\%) or income (31.7\%), and a patient's history of medication compliance (30.9\%; Table 5 in the ESM).

\subsection{Discrete-Choice Experiment}

In the DCE analysis, $22.4 \%$ of patients $(n=113 / 505)$ failed the dominant scenario test and were excluded from the main analysis. Mixed-logit DCE analysis was used to calculate model coefficients representing patients' preferences for different attribute levels, where positive coefficients indicate that the corresponding level is valued above average (Table 2). In terms of device, the insulin pen cartridge was most preferred (mean 0.36, standard error [SE] 0.07; $p<$ 0.001 ) followed by the insulin pen (mean -0.13 , SE 0.06; $p=0.04$ ) and the vial/syringe (mean -0.23 , SE $0.07 ; p$ $<0.001$ ). $\mathrm{HbA}_{1 \mathrm{c}}$ levels $>9 \%$ were least preferred (mean -1.72, SE 0.15), followed by $\mathrm{HbA}_{1 \mathrm{c}}$ 7.0-9.0\% (mean 0.35; SE 0.07), and $\mathrm{HbA}_{1 \mathrm{c}}$ levels $<7 \%$ were most preferred (mean 1.37, SE 0.13; all $p<0.001$ ). A $1 \%$ increase in the risk of minor hypoglycemia decreased the preference estimate by -0.03 (SE $0.00 ; p<0.001$ ), whereas increasing the number of major hypoglycemic episodes from 0 (mean 0.12 , SE 
Table 1 Patient demographics and ability-to-pay characteristics of the study population at baseline according to willingness-to-pay status

\begin{tabular}{|c|c|c|c|c|}
\hline Characteristic & $\begin{array}{l}\text { All patients } \\
(N=505)\end{array}$ & $\begin{array}{l}\text { WTP } \\
(N=487)\end{array}$ & $\begin{array}{l}\text { Not WTP } \\
(N=18)\end{array}$ & $P$ value $^{\mathrm{a}}$ \\
\hline Age, years & $56.4 \pm 11.1$ & $56.3(11.1)$ & $57.3(10.0)$ & 0.726 \\
\hline Male & $277(54.9)$ & $269(55.2)$ & $8(44.4)$ & 0.366 \\
\hline BMI, $\mathrm{kg} / \mathrm{m}^{2}$ & & & & 0.125 \\
\hline Underweight $(<18)$ & $1(0.2)$ & $1(0.2)$ & $0(0.0)$ & \\
\hline Normal $(18-<23)$ & $102(20.2)$ & $101(20.7)$ & $1(5.6)$ & \\
\hline Overweight $(23-<25)$ & $80(15.8)$ & $79(16.2)$ & $1(5.6)$ & \\
\hline Obese $(\geq 25)$ & $322(63.8)$ & $306(62.8)$ & $16(88.8)$ & \\
\hline \multicolumn{5}{|l|}{ Comorbidities $^{\mathrm{b}}$} \\
\hline Hypertension & $303(73.9)$ & $291(73.3)$ & $12(92.3)$ & 0.198 \\
\hline Hypercholesterolemia & $112(27.3)$ & $108(27.2)$ & $4(30.8)$ & 0.757 \\
\hline Neuropathy & $51(12.4)$ & $49(12.3)$ & $2(15.4)$ & 0.670 \\
\hline Kidney disease & $50(12.2)$ & $46(11.6)$ & $4(30.8)$ & 0.061 \\
\hline Stroke or heart disease & $50(12.2)$ & $48(12.1)$ & $2(15.4)$ & 0.665 \\
\hline Eye disease & $21(5.1)$ & $21(5.3)$ & $0(0.0)$ & 1.000 \\
\hline Lung disease & $18(4.4)$ & $17(4.3)$ & $1(7.7)$ & 0.477 \\
\hline Arthritis & $5(1.2)$ & $5(1.3)$ & $0(0.0)$ & 1.000 \\
\hline Depression and/or mental health issues & $3(0.7)$ & $2(0.5)$ & $1(7.7)$ & 0.092 \\
\hline Liver disease & $3(0.7)$ & $2(0.5)$ & $1(7.7)$ & 0.092 \\
\hline Cancer & $1(0.2)$ & $0(0.0)$ & $1(7.7)$ & 0.032 \\
\hline Other chronic conditions ${ }^{c}$ & $79(19.3)$ & $77(19.4)$ & $2(15.4)$ & 1.000 \\
\hline Missing & $95(18.8)$ & $90(17.8)$ & $5(1.0)$ & \\
\hline Number of family members/household & $4.6 \pm 2.1$ & $4.5 \pm 2.1$ & $5.7 \pm 3.7$ & 0.193 \\
\hline Number of children/household & & & & 0.549 \\
\hline 0 & $227(45.6)$ & $221(46.0)$ & $6(33.3)$ & \\
\hline 1 & $167(33.1)$ & $160(33.3)$ & $7(38.9)$ & \\
\hline$\geq 2$ & $104(20.7)$ & 99 (20.6) & $5(27.8)$ & \\
\hline Missing & $7(1.4)$ & $7(1.4)$ & $0(0.0)$ & \\
\hline Area of residence & & & & 1.000 \\
\hline Urban & $415(82.3)$ & $400(82.3)$ & $15(83.3)$ & \\
\hline Rural & $88(17.5)$ & $85(17.5)$ & $3(16.7)$ & \\
\hline Don't know & $1(0.2)$ & $1(0.2)$ & $0(0.0)$ & \\
\hline Missing & $1(0.2)$ & $1(0.2)$ & $0(0.0)$ & \\
\hline Number of rooms/household & $3.5 \pm 1.7$ & $3.5 \pm 1.6$ & $3.0 \pm 2.3$ & 0.339 \\
\hline Ownership of house & & & & 0.267 \\
\hline Owned & $450(89.8)$ & $432(89.4)$ & $18(100.0)$ & \\
\hline Rented & $50(10.0)$ & $50(10.4)$ & $0(0.0)$ & \\
\hline Other & $1(0.2)$ & $1(0.2)$ & $0(0.0)$ & \\
\hline Missing & $4(0.8)$ & $4(0.8)$ & $0(0.0)$ & \\
\hline Current work status & & & & 0.150 \\
\hline Employer & $55(10.9)$ & $54(11.1)$ & $1(5.6)$ & \\
\hline Self-employed & $135(26.7)$ & $134(27.5)$ & $1(5.6)$ & \\
\hline Waged worker & $38(7.5)$ & $37(7.6)$ & $1(5.6)$ & \\
\hline Unpaid working for family & $8(1.6)$ & $8(1.6)$ & $0(0.0)$ & \\
\hline Unpaid working for outsider & $0(0.0)$ & $0(0.0)$ & $0(0.0)$ & \\
\hline Unemployed & $14(2.8)$ & $14(2.9)$ & $0(0.0)$ & \\
\hline Full-time student & $2(0.4)$ & $2(0.4)$ & $0(0.0)$ & \\
\hline Homemaker & $154(30.5)$ & $147(30.2)$ & $7(38.9)$ & \\
\hline Retired & 75 (14.9) & $69(14.2)$ & $6(33.3)$ & \\
\hline Disabled & $0(0.0)$ & $0(0.0)$ & $0(0.0)$ & \\
\hline Others & $24(4.8)$ & $22(4.5)$ & $2(11.1)$ & \\
\hline
\end{tabular}


Table 1 (continued)

\begin{tabular}{llllc}
\hline Characteristic & $\begin{array}{l}\text { All patients } \\
(N=505)\end{array}$ & $\begin{array}{l}\text { WTP } \\
(N=487)\end{array}$ & $\begin{array}{l}\text { Not WTP } \\
(N=18)\end{array}$ & $P$ value $^{\mathrm{a}}$ \\
\hline Annual household income, INR & & & & 0.907 \\
$<150,000$ & $123(24.8)$ & $118(24.6)$ & $5(27.8)$ & \\
$150,000-340,000$ & $241(48.5)$ & $233(48.6)$ & $8(44.4)$ & \\
$>340,000-1,700,000$ & $122(24.6)$ & $117(24.4)$ & $5(27.8)$ \\
$>1,700,000$ & $11(2.2)$ & $11(2.3)$ & $0(0.0)$ & \\
Missing & $8(1.6)$ & $8(1.6)$ & $0(0.0)$ & \\
Health insurance status & & & \\
No health insurance & $250(50.1)$ & $240(49.9)$ & $10(55.6)$ & \\
Public health insurance & $102(20.4)$ & $97(20.2)$ & $5(27.8)$ \\
Private health insurance & $123(24.7)$ & $120(25.0)$ & $3(16.7)$ \\
Work-related health insurance & $24(4.8)$ & $24(5.0)$ & $0(0.0)$ & \\
Missing & $6(1.2)$ & $6(1.2)$ & $0(0.0)$ & \\
\hline
\end{tabular}

$\%$ percentage of total population, BIAsp 30 biphasic insulin aspart 30/70, BMI body mass index, INR Indian rupees, $n$ number of patients, $N$ total number of patients, $W T P$ willing to pay

Data are $\mathrm{n}(\%)$ or mean \pm standard deviation. The denominator for calculating the proportion of missing data was $n=505$

a Patients WTP for BIAsp 30 versus patients not WTP; $P$ values calculated using t-test for continuous variables and Fisher's exact test or chi-squared test for categorical variables

${ }^{\mathrm{b}}$ Denominator for percentage calculation is $n=410$

${ }^{\mathrm{c}}$ Includes thyroid disorders, anemia, hyperuricemia, dyslipidemia/hyperlipidemia, peripheral vascular disease, gastrointestinal disorders (gastritis, pancreatitis), diabetic foot/leg ulcer, benign prostatic hyperplasia, polycystic ovarian disorder, urticaria, piles, deep vein thrombosis, and vertigo

0.04 ) to 1 (mean -0.12 , SE 0.04 ) decreased the preference estimate by $0.24(p=0.01)$. In terms of dosing flexibility, the ability to administer treatment immediately before a meal had a preference estimate of 0.01 (SE 0.04) compared with a preference estimate of -0.01 (SE 0.04 ) for administering 30 minutes before a meal, although this finding was not significant $(p=0.84)$. The preference estimate decreased by 0.09 (SE 0.01$)$ for each INR100 increase in the cost of a medication $(p<0.001)$.

The SDs were significant for most of the attribute levels, indicating heterogeneity between patients with regards to attribute preferences (Table 2). The SD for dosing flexibility was not significant $(p=0.43)$, so there was no associated heterogeneity. On average, per month, patients were WTP INR3576 (95\% CI 2755-4398) for improved glycemic control (reducing their $\mathrm{HbA}_{1 \mathrm{c}}$ from $>9.0$ to $<7.0 \%$ ), INR688 (95\% CI 383-994) for a device upgrade (syringe to Penfill ${ }^{\circledR}$ ), and INR327 (95\% CI 95-560) to avoid major hypoglycemia; further, patients would need to be compensated INR44 (95\% CI 56-32) per minor hypoglycemic event (Table 3). DCE results from the sensitivity analysis (including all patients irrespective of their performance on the dominant scenario task) were generally consistent with the main analysis (Table 4).

\subsection{Diabetes Treatment Satisfaction Questionnaire}

There was a significant improvement from baseline in DTSQ score, perceived frequency of hyperglycemia, and perceived frequency of hypoglycemia among patients WTP at week 12 (all $p<0.0001$ ), whereas only change in perceived frequency of hyperglycemia was significant among those not WTP at week 12 (Table 5). The increase in DTSQ score at week 12 was significantly higher among those WTP than those not WTP $(p=0.040)$, but no difference was observed according to WTP status in the perceived frequency of hyperglycemia/hypoglycemia (Table 5).

\subsection{Treatment-Related Impact Measure for Diabetes Device}

The mean bother domain score significantly $(p<0.0001)$ increased in the overall study population from baseline to week 12, with a higher score indicating less bother (Table 6). Similarly, the mean function domain score was significantly $(p<0.0001)$ increased in the overall population from baseline to week 12, with a higher score indicating greater function. As shown in Table 6, there were no significant differences in the change in mean domain scores among patient groups (WTP/not WTP). 
Table 2 Model results for mean coefficient and standard deviation estimates of study attributes for the main analysis $(n=392)$

\begin{tabular}{|c|c|c|c|c|c|c|c|}
\hline \multirow[t]{2}{*}{ Attribute } & \multirow[t]{2}{*}{ Levels } & \multicolumn{3}{|c|}{ Estimated mean } & \multicolumn{3}{|c|}{ Estimated SD } \\
\hline & & Coefficient & SE & $P$ value & Coefficient & SE & $P$ value \\
\hline \multirow[t]{3}{*}{ Device } & Vial/syringe & -0.23 & 0.07 & $<0.001$ & 0.70 & 0.19 & $<0.001$ \\
\hline & Insulin pen & -0.13 & 0.06 & 0.04 & 0.53 & 0.10 & $<0.001$ \\
\hline & Insulin pen cartridge & 0.36 & 0.07 & $<0.001$ & 0.17 & 0.16 & 0.29 \\
\hline \multirow[t]{3}{*}{$\mathrm{HbA}_{1 \mathrm{c}}$} & $<7 \%$ & 1.37 & 0.13 & $<0.001$ & 1.36 & 0.14 & $<0.001$ \\
\hline & $7-9 \%$ & 0.35 & 0.07 & $<0.001$ & 0.37 & 0.13 & $<0.001$ \\
\hline & $>9 \%$ & -1.72 & 0.15 & $<0.001$ & 1.73 & 0.20 & $<0.001$ \\
\hline Minor hypoglycemia & Per $1 \%$ increase in risk & -0.03 & 0.00 & $<0.001$ & 0.03 & 0.00 & $<0.001$ \\
\hline \multirow[t]{2}{*}{ Major hypoglycemia } & 0 & 0.12 & 0.04 & 0.01 & 0.42 & 0.07 & $<0.001$ \\
\hline & 1 & -0.12 & 0.04 & 0.01 & 0.42 & 0.07 & $<0.001$ \\
\hline \multirow[t]{2}{*}{ Flexibility } & 0 min before meal & 0.01 & 0.04 & 0.84 & 0.12 & 0.15 & 0.43 \\
\hline & 30 min before meal & -0.01 & 0.04 & 0.84 & 0.12 & 0.15 & 0.43 \\
\hline Cost & Per INR100 increase & -0.09 & 0.01 & $<0.001$ & 0.12 & 0.01 & $<0.001$ \\
\hline
\end{tabular}

Patients who failed the dominant scenario task $(n=113)$ and one patient who did not answer the dominant scenario task were excluded from the main analysis

$H b A_{l c}$ glycated hemoglobin, INR Indian rupees, $n$ number of patients, $S D$ standard deviation, $S E$ standard error

\subsection{Diabetes Pen Experience Measure}

The DPEM questionnaire was answered by all 505 (100.0\%) patients at week 12. In terms of learning how to use the pen, $56.2 \%$ reported no difficulty at all, $40.6 \%$ reported little to some difficulty, and only $2.2 \%$ found it very difficult. In terms of ease or difficulty to perform various activities with the pen, 51.1-67.8\% did not find it difficult at all. Less than $10 \%$ of patients found one or other pen-related activity to be very difficult or extremely difficult. Unexpectedly, approximately $45 \%$ responded that the pen helped with letting them know when to take their next dose or the amount of the next dose. More than half of patients were not at all bothered by the needle or pen size, the potential for pen jamming, or the steps required to prepare the injection. Approximately two-thirds (60.4-65.8\%) reported being very confident or extremely confident that they were using the pen correctly, setting the correct dose on the pen, and that the pen had delivered the right dose. Almost half of patients did not find it difficult at all to use the pen properly, and $75.1 \%$ were, overall, very satisfied or extremely satisfied with the pen (Table 6 in the ESM).

\section{Discussion}

The majority of patients $(96.4 \%)$ who were switched from BHI treatment in syringes/vials to BIAsp 30 in an insulin pen by their physician, continued treatment after 12 weeks and were WTP for their treatment. This therapeutic switch
Table 3 Patients' willingness to pay for each treatment and treatment device attribute

\begin{tabular}{lll}
\hline Attribute & Levels & WTP in INR (95\% CI) \\
\hline Device & Vial/syringe (base) & NR \\
& Insulin pen & $8.49(-257.13-274.10)$ \\
& Insulin pen cartridge & $688.42(382.86-993.97)$ \\
$\mathrm{HbA}_{1 \mathrm{c}}$ & $<7.0 \%$ & $3576.33(2754.71-4397.96)$ \\
& $7.0-9.0 \%$ & $2313.48(1739.43-2887.52)$ \\
Minor hypoglycemia & $>9.0 \%$ (base) & $\mathrm{NR}$ \\
Major hypoglycemia & Per 1\% increase in risk & $-43.78(-56.06$ to -31.51$)$ \\
& 0 & $327.38(95.11-559.65)$ \\
Flexibility & 1 (base) & $\mathrm{NR}$ \\
& 0 min before meal (base) & $\mathrm{NR}$ \\
\hline
\end{tabular}

$C I$ confidence interval, $H b A_{l c}$ glycated hemoglobin, INR Indian rupees, $N R$ not reported, WTP willingness to pay 
Table 4 Model results for mean coefficient and standard deviation estimates of study attributes for the sensitivity analysis $(n=505)$

\begin{tabular}{|c|c|c|c|c|c|c|c|}
\hline \multirow[t]{2}{*}{ Attribute } & \multirow[t]{2}{*}{ Levels } & \multicolumn{3}{|c|}{ Estimated mean } & \multicolumn{3}{|c|}{ Estimated SD } \\
\hline & & Coefficient & SE & $P$ value & Coefficient & SE & $P$ value \\
\hline \multirow[t]{3}{*}{ Device } & Vial/syringe & -0.16 & 0.05 & $<0.001$ & 0.49 & 0.18 & 0.01 \\
\hline & Insulin pen & -0.06 & 0.05 & 0.24 & 0.40 & 0.07 & $<0.001$ \\
\hline & Insulin pen cartridge & 0.22 & 0.05 & $<0.001$ & 0.09 & 0.16 & 0.56 \\
\hline \multirow[t]{3}{*}{$\mathrm{HbA}_{1 \mathrm{c}}$} & $<7 \%$ & 1.01 & 0.08 & $<0.001$ & 1.14 & 0.09 & $<0.001$ \\
\hline & $7-9 \%$ & 0.26 & 0.05 & $<0.001$ & 0.33 & 0.09 & $<0.001$ \\
\hline & $>9 \%$ & -1.27 & 0.09 & $<0.001$ & 1.47 & 0.14 & $<0.001$ \\
\hline Minor hypoglycemia & Per $1 \%$ increase in risk & -0.02 & 0.00 & $<0.001$ & 0.02 & 0.00 & $<0.001$ \\
\hline \multirow[t]{2}{*}{ Major hypoglycemia } & 0 & 0.06 & 0.03 & 0.07 & 0.27 & 0.06 & $<0.001$ \\
\hline & 1 & -0.06 & 0.03 & 0.07 & 0.27 & 0.06 & $<0.001$ \\
\hline \multirow[t]{2}{*}{ Flexibility } & $0 \mathrm{~min}$ before meal & -0.02 & 0.03 & 0.54 & 0.16 & 0.07 & 0.02 \\
\hline & 30 min before meal & 0.02 & 0.03 & 0.54 & 0.16 & 0.07 & 0.02 \\
\hline Cost & Per INR100 increase & -0.06 & 0.01 & $<0.001$ & 0.09 & 0.01 & $<0.001$ \\
\hline
\end{tabular}

The sensitivity analysis was conducted for the full analysis set

$H b A_{l c}$ glycated hemoglobin, INR Indian rupees, $n$ number of patients, $S D$ standard deviation, $S E$ standard error was associated with higher treatment satisfaction and diabetes device scores at week 12 compared with scores at baseline. Furthermore, the treatment attributes that were most important to patients were improvement in glycemic control, a device upgrade (vial and syringe to Penfill ${ }^{\circledR}$ ), and avoidance of major hypoglycemia.

The study population represents relatively affluent patients with T2DM receiving treatment in private clinics and hospitals across India. Treating physicians switched patients to BIAsp 30 for a number of reasons, the most common of which were to improve patients' blood sugar control and to reduce the risk of hypoglycemia. Physicians' assessment of the likelihood of study patients continuing to use BIAsp 30 was high at $98.2 \%$ and attributed to their knowledge of their patients' compliance, family, and income. This suggests that physicians in India who prescribe premix insulins can precisely predict which patients can afford and will pay to upgrade their insulin and device.

In the DCE, patients expressed preferences for different treatment and device attributes. The mixed logit model showed that patients preferred an insulin pen cartridge over an insulin pen but preferred either to a vial/syringe. It is perhaps surprising that patients placed a greater value on the switch from a vial/syringe to a pre-filled insulin pen cartridge (for use in an insulin pen) than the switch to an insulin pen (complete with pre-filled insulin pen cartridge). However, the authors speculate that the move from a vial/ syringe to an automated delivery device would have had a substantial impact on device satisfaction, and this may have diminished our ability to distinguish more subtle preferences between devices.
Overall, patients were WTP to reduce their $\mathrm{HbA}_{1 \mathrm{c}}$ levels and to avoid minor and/or major hypoglycemic episodes, but there was significant preference heterogeneity for the majority of attribute levels. In contrast, patients were not WTP for dosing flexibility and they did not require compensation for insulin to be administered 30 min before a meal rather than at the point of eating ( $0 \mathrm{~min}$ before a meal). This finding is somewhat surprising as the flexible injection timing relative to meal timing with BIAsp 30 provides greater convenience and flexibility than BHI and results in significantly greater treatment satisfaction and improved quality of life [28, 29], and the authors expected flexibility to be an important attribute from patients' perspectives. Possible explanations for this finding include a relatively low preference for this attribute in the study population due to consistent and predictable meal timings, acceptance of the previous BHI dosing regimen, or poor adherence to the recommended injection-meal intervals with BHI.

Switching to BIAsp 30 from BHI saw a significant improvement in patient-reported outcomes. As observed in the DTSQ, the perceived frequency of both hypoglycemia and hyperglycemia was improved in the WTP group after just 12 weeks of treatment with BIAsp 30. This suggests that switching to BIAsp 30 from BHI helps to reduce glycemic variability, and this switch in medication could potentially help prevent the occurrence of dangerous hypoglycemic episodes that can occur as a result of using improved insulin delivery systems. The mean bother domain and function domain scores of the TRIM-DD were also significantly improved from baseline in the overall study population and in the subgroups, regardless of WTP status. Results of the 


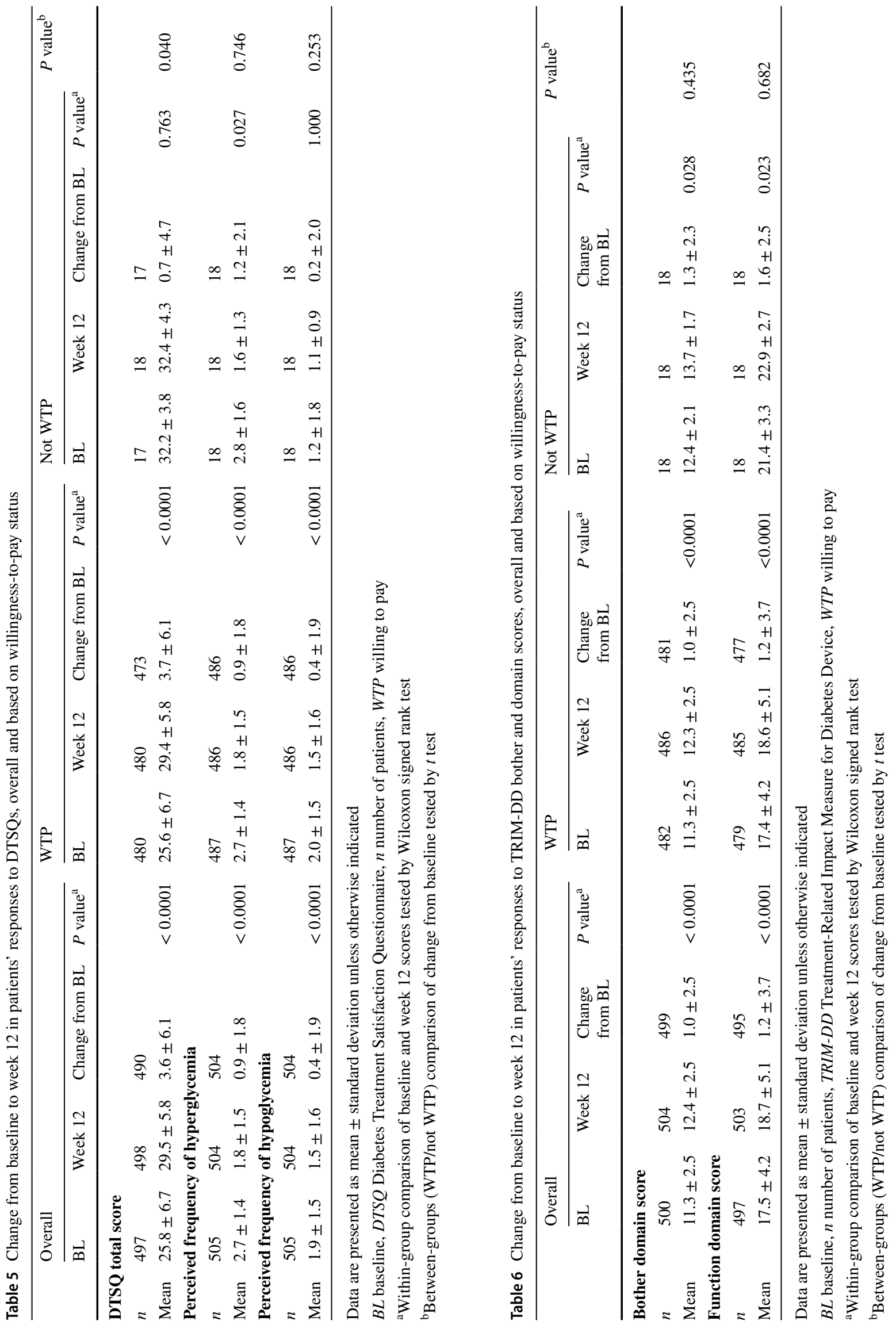


DPEM questionnaire showed that approximately two-thirds of patients were very confident or extremely confident using the pen, and $75.1 \%$ were overall very satisfied or extremely satisfied with the pen.

Assessment of WTP has become a key aspect of healthcare research and has been applied to a wide range of interventions in different markets, although data evaluating WTP for insulin therapy are limited [17, 18, 20]. This study has a number of strengths. It is the first of its kind to be conducted in India across various cities, representing different regions of the country, and reporting WTP for BIAsp 30 in a real-world population with T2DM. This study highlights the importance of different attributes of insulin therapy and injectable devices to patients with T2DM. Given the realworld nature of this study, the results are generalizable to the adult population with T2DM in India who are switched, as part of routine private clinical practice, from $\mathrm{BHI}$ in vials to BIAsp 30 in an insulin pen device, and these patients are likely WTP for BIAsp 30 according to their treating physician.

This study also has a number of limitations. As the study sites were selected based on a non-probability sampling technique, findings may not be applicable to other clinic types (e.g., clinics catering to a population who might not be able to afford BIAsp 30 treatment). There was a recruitment bias in that only patients who were thought to be able to pay for treatment were included in the study. However, we assume this represents normal clinical practice when prescribing a treatment in an out-of-pocket market. This recruitment bias is likely to have resulted in a positive WTP bias and may have influenced other measures of treatment satisfaction after switching. It should also be considered that physicians successfully predicted whether patients were WTP for BIAsp 30 treatment, but the study does not indicate whether physicians are also able to predict those unwilling to pay for treatment. Furthermore, data collection reflected routine clinical practice rather than mandatory assessments at prespecified time points; hence, data for some of the questionnaires were missing. As this was a non-interventional, open-label study, and patients were not randomized, there may be potential confounding factors. Thus, study findings, such as the improvement in treatment satisfaction, should be interpreted cautiously. Furthermore, sparse data bias was an issue: since the majority of patients were still using BIAsp 30 at week 12, there were very few patients in the "not WTP" category. Lastly, DCEs are based on several theoretical assumptions regarding respondents' decision making that may not hold true in real-world settings; for instance, some respondents may apply simplified decision-making strategies incorporating dominant preferences for one highly valued attribute rather than utilizing trade-offs [30].

\section{Conclusion}

After 12 weeks' BIAsp 30 treatment, the vast majority of Indian patients with T2DM previously treated with BHI continued to pay for an upgraded insulin and an improved insulin-delivery device, reported a significant improvement in patient-reported outcomes, and were WTP for BIAsp 30 in an insulin pen. This therapeutic switch was observed to improve treatment and device satisfaction. The results of this study may help to increase prescribers' understanding of the ability to pay for and WTP for BIAsp 30 among patients with T2DM in an out-of-pocket market such as India.

Acknowledgements The authors thank the study participants, investigators, and coordinators. They also thank Bharathi Bhatt for critical review of the manuscript during the drafting stages. Medical writing and submission support were provided by Samuel Bestall, $\mathrm{PhD}$, and Clare Lowe, of Watermeadow Medical, an Ashfield Company, part of UDG Healthcare plc, funded by Novo Nordisk.

\section{Declarations}

Funding This study and article processing charges were funded by Novo Nordisk.

Conflict of interest NAR and LLNH are employees of the sponsor (at Novo Nordisk Health Care AG) and own shares in the company. JK is in the Speaker's bureau for Novo Nordisk. SM, PA, and AJA have no conflicts of interest that are directly relevant to the content of this article.

Ethics approval The study was conducted in accordance with Good Pharmacoepidemiology Practice (GPP), ethics review board approval, and the Declaration of Helsinki.

Consent to participate Written informed consent was obtained from all individual participants included in the study before any study-related activities took place.

Consent for publication Not applicable.

Data availability The datasets generated and/or analyzed during the current study are available from the corresponding author on reasonable request.

Code availability Not applicable.

Related manuscript No authors have a related or duplicate manuscript under consideration or accepted for publication elsewhere.

Author contributions Study conception and design were contributed to by Lise Lotte Nystrup Husemoen, and Nicolai A. Rhee. Data collection was carried out by Sreenivasa Murthy, Pankaj Aneja, Arthur Asirvatham, and Jothydev Kesavadev. All authors critically reviewed the manuscript during the drafting stages and share in the final responsibility for the content of the manuscript, as well as the decision to submit it for publication.

Open Access This article is licensed under a Creative Commons Attribution-NonCommercial 4.0 International License, which permits any non-commercial use, sharing, adaptation, distribution and reproduction 
in any medium or format, as long as you give appropriate credit to the original author(s) and the source, provide a link to the Creative Commons licence, and indicate if changes were made. The images or other third party material in this article are included in the article's Creative Commons licence, unless indicated otherwise in a credit line to the material. If material is not included in the article's Creative Commons licence and your intended use is not permitted by statutory regulation or exceeds the permitted use, you will need to obtain permission directly from the copyright holder. To view a copy of this licence, visit http://creativecommons.org/licenses/by-nc/4.0/.

\section{References}

1. Cho NH, Shaw JE, Karuranga S, et al. IDF Diabetes Atlas: global estimates of diabetes prevalence for 2017 and projections for 2045. Diabetes Res Clin Pract. 2018;138:271-81. https://doi. org/10.1016/j.diabres.2018.02.023 (PubMed PMID: 29496507).

2. International Diabetes Federation. IDF Diabetes Atlas 8th edition 2017. http://www.diabetesatlas.org/. Accessed 27 Feb 2019.

3. Home P, Riddle M, Cefalu WT, et al. Insulin therapy in people with type 2 diabetes: opportunities and challenges? Diabetes Care. 2014;37(6):1499-508. https://doi.org/10.2337/dc132743 (PubMedPMID: 24855154; PubMed Central PMCID: PMCPMC5131884).

4. Mohan V, Kalra S, Kesavadev J, et al. Consensus on initiation and intensification of premix insulin in type 2 diabetes management. J Assoc Physicians India. 2017;65(4):59-73 (PubMed PMID: 28527166)

5. Kalra S, Balhara YP, Sahay BK, et al. Why is premixed insulin the preferred insulin? Novel answers to a decade-old question. $\mathrm{J}$ Assoc Physicians India. 2013;61(1 Suppl):9-11 (PubMed PMID: 24482980)

6. Baruah MP, Kalra S, Bose S, et al. An audit of insulin usage and insulin injection practices in a large Indian cohort. Indian J Endocrinol Metab. 2017;21(3):443-52. https://doi.org/10.4103/ijem. IJEM_548_16 (PubMed PMID: 28553603; PubMed Central PMCID: PMCPMC5434731. eng).

7. Mohan V, Shah SN, Joshi SR, et al. Current status of management, control, complications and psychosocial aspects of patients with diabetes in India: results from the DiabCare India 2011 Study. Indian J Endocrinol Metab. 2014;18(3):370-8. https://doi. org/10.4103/2230-8210.129715 (PubMedPMID: 24944934; PubMed Central PMCID: PMCPMC4056138.eng).

8. Asakura T, Seino H, Nakano R, et al. A comparison of the handling and accuracy of syringe and vial versus prefilled insulin pen (FlexPen). Diabetes Technol Ther. 2009;11(10):657-61. https:// doi.org/10.1089/dia.2009.0006 (PubMed PMID: 19821758;eng).

9. Brunton S. Initiating insulin therapy in type 2 diabetes: benefits of insulin analogs and insulin pens. Diabetes Technol Ther. 2008;10(4):247-56. https://doi.org/10.1089/dia.2008.0287 (PubMed PMID: 18715198; eng).

10. Korytkowski M, Niskanen L, Asakura T. FlexPen: addressing issues of confidence and convenience in insulin delivery. Clin Ther. 2005;27(Suppl B):S89-100 (PubMed PMID: 16519040; eng).

11. Korytkowski M, Bell D, Jacobsen C, et al. A multicenter, randomized, open-label, comparative, two-period crossover trial of preference, efficacy, and safety profiles of a prefilled, disposable pen and conventional vial/syringe for insulin injection in patients with type 1 or 2 diabetes mellitus. Clin Ther. 2003;25(11):283648 (PubMed PMID: 14693308; eng)

12. Pfutzner A, Bailey T, Campos C, et al. Accuracy and preference assessment of prefilled insulin pen versus vial and syringe with diabetes patients, caregivers, and healthcare professionals. Curr
Med Res Opin. 2013;29(5):475-81. https://doi.org/10.1185/03007 995.2013.775112 (PubMed PMID: 23402225;eng).

13. Weyer C, Heise T, Heinemann L. Insulin aspart in a $30 / 70$ premixed formulation. Pharmacodynamic properties of a rapid-acting insulin analog in stable mixture. Diabetes Care. 1997;20(10):1612-4 (PubMed PMID: 9314644).

14. Liebl A, Prusty V, Valensi P, et al. Ten years of experience with biphasic insulin aspart 30: from drug development to the latest clinical findings. Drugs. 2012;72(11):1495-520. https://doi. org/10.2165/11635490-000000000-00000 (PubMedPMID: 22818015; PubMed Central PMCID: PMCPMC3590411).

15. Garber AJ, Wahlen J, Wahl T, et al. Attainment of glycaemic goals in type 2 diabetes with once-, twice-, or thrice-daily dosing with biphasic insulin aspart 70/30 (The 1-2-3 study). Diabetes Obes Metab. 2006;8(1):58-66. https://doi.org/10.111 1/j.1463-1326.2005.00563.x (PubMed PMID: 16367883).

16. Le Gall-Ely M. Definition, measurement and determinants of the consumer's willingness to pay: a critical synthesis and avenues for further research. Recherche et Applications en Marketing (English Edition). 2009;24(2):91-112. https://doi.org/10.1177/2051570709 02400205.

17. Feher MD, Brazier J, Schaper N, et al. Patients' with type 2 diabetes willingness to pay for insulin therapy and clinical outcomes. BMJ Open Diabetes Res Care. 2016;4(1):e000192. https://doi. org/10.1136/bmjdrc-2016-000192 (PubMed PMID: 27158518; PubMed Central PMCID: PMCPMC4853803).

18. Bogelund M, Vilsboll T, Faber J, et al. Patient preferences for diabetes management among people with type 2 diabetes in Denmark-a discrete choice experiment. Curr Med Res Opin. 2011;27(11):2175-83. https://doi.org/10.1185/03007 995.2011.625404 (PubMed PMID: 21981417).

19. Hauber AB, Han S, Yang JC, et al. Effect of pill burden on dosing preferences, willingness to pay, and likely adherence among patients with type 2 diabetes. Patient Prefer Adherence. 2013;7:937-49. https://doi.org/10.2147/ppa.S4346 5 (PubMed PMID: 24086104; PubMed Central PMCID: PMCPMC3786815.eng).

20. Davey P, Grainger D, MacMillan J, et al. Economic evaluation of insulin lispro versus neutral (regular) insulin therapy using a willingness-to-pay approach. Pharmacoeconomics. 1998;13(3):34758. https://doi.org/10.2165/00019053-199813030-00009 (PubMed PMID: 10178660).

21. Tikkanen R, Osborn R, Mossialos E, et al. India: The CommonWealth Fund; 2020. https://www.commonwealthfund.org/inter national-health-policy-center/countries/india. Accessed Aug 2020

22. National Health Systems Resource Centre. National Health Accounts Estimates for India (2016-17). New Delhi: Ministry of Health and Family Welfare, Government of India; 2019.

23. Bradley $\mathrm{C}$. The diabetes treatment satisfaction questionnaire: DTSQ. In: Handbook of psychology diabetes: a guide to psychological measurement in diabetes research practice. Chur: Harwood Academic Publishers; 1994. p. 111-32.

24. Brod M, Christensen T, Hammer M, et al. Examining the ability to detect change using the TRIM-Diabetes and TRIM-Diabetes Device measures. Qual Life Res. 2011;20(9):1513-8. https://doi. org/10.1007/s11136-011-9886-7 (PubMed PMID: 21424338; PubMed Central PMCID: PMCPMC3195684).

25. Bridges JF, Hauber AB, Marshall D, et al. Conjoint analysis applications in health-a checklist: a report of the ISPOR Good Research Practices for Conjoint Analysis Task Force. Value Health. 2011;14(4):403-13. https://doi.org/10.1016/j. jval.2010.11.013 (PubMed PMID: 21669364;eng).

26. Mühlbacher A, Johnson FR. Choice experiments to quantify preferences for health and healthcare: State of the practice. Appl Health Econ Health Policy. 2016;14(3):253-66. https 
://doi.org/10.1007/s40258-016-0232-7 (PubMed PMID: 26992386; eng).

27. X-Rates.com. Monthly average 2018. https://www.X-rates .com/average/?from $=I N R \&$ to $=E U R \&$ amount $=1 \&$ year $=2018$. Accessed Aug 2020

28. Boehm BO, Home PD, Behrend C, et al. Premixed insulin aspart 30 vs premixed human insulin 30/70 twice daily: a randomized trial in Type 1 and Type 2 diabetic patients. Diabetic Med. 2002;19(5):393-9. https://doi.org/10.104 6/j.1464-5491.2002.00733.x (PubMed PMID: 12027927; eng).
29. Garber AJ, Ligthelm R, Christiansen JS, et al. Premixed insulin treatment for type 2 diabetes: analogue or human? Diabetes Obes Metab. 2007;9(5):630-9. https://doi.org/10.111 1/j.1463-1326.2006.00654.x (PubMed PMID: 17697056;eng).

30. Veldwijk J, Determann D, Lambooij MS, et al. Exploring how individuals complete the choice tasks in a discrete choice experiment: an interview study. BMC Med Res Methodol. 2016;21(16):45. https://doi.org/10.1186/s12874-016-01404 (PubMed PMID: 27098746; PubMed Central PMCID: PMCPMC4839138.eng).

\section{Affiliations}

\section{Sreenivasa Murthy ${ }^{1} \cdot$ Pankaj Aneja ${ }^{2} \cdot$ Arthur Joseph Asirvatham $^{3} \cdot$ Lise Lotte N. Husemoen $^{4}$ Nicolai A. Rhee ${ }^{5}$. Jothydev Kesavadev ${ }^{6}$}

Pankaj Aneja

drpankajaneja@gmail.com

Arthur Joseph Asirvatham

ajasirvathamresearch@yahoo.in

Lise Lotte N. Husemoen

LSHU@ novonordisk.com

Nicolai A. Rhee

NCRH@ novonordisk.com

Jothydev Kesavadev

jothydev@gmail.com
1 LifeCare Hospital and Research Centre, Bangalore, Karnataka, India

2 Max Super Speciality Hospital, Shalimar Bagh, New Delhi, India

3 Arthur Asirvatham Hospital, Madurai, Tamil Nadu, India

4 Novo Nordisk A/S, Søborg, Denmark

5 Novo Nordisk Health Care AG, Zurich, Switzerland

6 Jothydev's Diabetes Research Center, Trivandrum, Kerala, India 